B. E. Brown • F. M. Mahroof • N. L. Cook •

D. M. van Reyk - M. J. Davies

\title{
Hydrazine compounds inhibit glycation of low-density lipoproteins and prevent the in vitro formation of model foam cells from glycolaldehyde-modified low-density lipoproteins
}

Received: 22 August 2005 / Accepted: 10 November 2005 / Published online: 8 February 2006

C) Springer-Verlag 2006

\begin{abstract}
Aims/hypothesis: Previous studies have shown that glycation of LDL by methylglyoxal and glycolaldehyde, in the absence of significant oxidation, results in lipid accumulation in macrophage cells. Such 'foam cells' are a hallmark of atherosclerosis. In this study we examined whether LDL glycation by methylglyoxal or glycolaldehyde, and subsequent lipid loading of cells, can be inhibited by agents that scavenge reactive carbonyls. Such compounds may have therapeutic potential in diabetesassociated atherosclerosis. Materials and methods: LDL was glycated with methylglyoxal or glycolaldehyde in the absence or presence of metformin, aminoguanidine, Girard's reagents $\mathrm{P}$ and T, or hydralazine. LDL modification was characterised by changes in mobility (agarose gel electrophoresis), cross-linking (SDS-PAGE) and loss of amino acid residues (HPLC). Accumulation of cholesterol and cholesteryl esters in murine macrophages was assessed by HPLC. Results: Inhibition of LDL glycation was detected with equimolar or greater concentrations of the scavengers over the reactive carbonyl. This inhibition was structure-dependent and accompanied by a modulation of cholesterol and cholesteryl ester accumulation. With aminoguanidine, Girard's reagent $\mathrm{P}$ and hydralazine, cellular sterol levels returned to control levels despite incomplete inhibition of LDL modification. Conclusions/ interpretation: Inhibition of LDL glycation by interception of the reactive aldehydes that induce LDL modification prevents lipid loading and model foam cell formation in murine macrophage cells. Carbonyl-scavenging reagents, such as hydrazines, may therefore help inhibit
\end{abstract}

B. E. Brown · F. M. Mahroof · N. L. Cook · M. J. Davies $(\bowtie)$

Free Radical Group, The Heart Research Institute,

145 Missenden Road, Camperdown,

Sydney, NSW 2050, Australia

e-mail: daviesm@hri.org.au

Tel.: +61-2-95503560

Fax: $+61-2-95503302$

D. M. van Reyk

Department of Health Sciences,

University of Technology Sydney,

Sydney, NSW, Australia
LDL glycation in vivo and prevent diabetes-induced atherosclerosis.

Keywords Aldehydes - Apolipoprotein B ·

Atherosclerosis - Cholesterol esters · Foam cells · Glycation · Hydrazines · Low-density lipoproteins ·

Macrophages $\cdot$ Protein modification

Abbreviations apoB: apolipoprotein B-100 - OPA: $o$ phthaldialdehyde $\cdot$ REM: relative electrophoretic mobility

\section{Introduction}

Diabetic complications are the major cause of mortality and morbidity in patients with diabetes. These complications affect both the microvascular and the macrovascular system. Disease of the microvascular system leads to damage of the retina, nephrons and peripheral nerves, whereas macrovascular disease is associated with accelerated atherosclerosis in the coronary, peripheral and carotid arteries [1]. Cardiovascular disease is responsible for approximately $50 \%$ of deaths in people with diabetes [2].

A number of features of diabetes mellitus, including chronic hyperglycaemia, insulin resistance, dyslipidaemia, and abnormalities of haemostasis, are thought to contribute to atherosclerosis [3, 4]. Macrovascular disease appears in most patients with type 2 diabetes at or near the time of first diagnosis, consistent with a shared underlying pathogenesis [3].

An early and persistent feature of atherosclerotic lesions is the presence of lipid-laden (foam) cells, arising from cholesterol and cholesteryl ester accumulation in macrophages in the intima of the artery wall [5]. LDL are the likely source of this lipid. The expression of native LDL receptors on arterial cell types is tightly controlled and regulated by feedback [6]. In contrast, the uncontrolled uptake of modified LDL, which results in foam cell formation, occurs via alternative receptors, including CD36, CD68 and scavenger receptors [6,7]. A number of LDL modifications, including oxidation, aggregation, 
chemical modification and the formation of immune complexes $[6,8]$, are recognised by these receptors.

Of particular relevance to diabetes-associated atherosclerosis is the role of glucose (or species derived from glucose) in inducing LDL modification [9, 10]. Previous studies have proposed multiple mechanisms, including glycation and glycoxidation reactions [4, 9]. Glycation of LDL involves the covalent binding of aldehyde groups of glucose, or low-molecular-mass compounds derived from glucose or metabolic processes, to reactive amines (e.g. Lys and Arg side-chains, N-terminus) and thiol groups (Cys) on the single apolipoprotein B-100 (apoB) protein molecule of the particle [11-13]. The initial product of such reactions is an unstable Schiff base, which undergoes subsequent rearrangement to yield Amadori products, such as fructoselysine. Glycoxidation consists of two related processes: oxidation of protein-bound sugars (e.g. those from glycation) and oxidation of free glucose and its products. Each mechanism can generate free radicals that can modify LDL, and hence potentially play a role in the enhanced cellular uptake of modified LDL $[12,14-16]$.

The species arising from glycation and glycoxidation reactions can undergo further reactions to give complex end-products, often termed AGE; many of these are incompletely characterised [9, 12]. Elevated levels of AGE have been reported in patients with diabetes [17]. Some AGE, such as $N^{\varepsilon}$-carboxymethyl- and $N^{\varepsilon}$-carboxyethyl-lysines and pentosidine, accumulate with age on tissue proteins, and at an increased rate in LDL and atherosclerotic lesions from patients with diabetes $[16,18-20] . \quad N^{\varepsilon}$-Carboxymethyllysine and $N^{\varepsilon}$-carboxyethyllysine are formed on reaction of Lys residues with low-molecular-mass aldehydes (glyoxal/glycolaldehyde and methylglyoxal, respectively) arising from glucose and metabolic pathways [21], providing evidence for a role of such aldehydes in diabetes-induced complications. These aldehydes are present at elevated levels in the plasma of patients with diabetes [22, 23].

We have shown previously that glycation of LDL by reactive aldehydes such as glycolaldehyde, in the absence of (glyc)oxidation, is sufficient for rapid lipid accumulation by macrophage cells [24]. This aldehyde-mediated 'carbonyl stress' [16] may therefore facilitate lipid accumulation in cells in the artery wall, and promote atherosclerosis in patients with diabetes. Hydrazine compounds (of general structure R-NHNH $\mathrm{H}_{2}$ ) react rapidly with carbonyl compounds (aldehydes and ketones), and may therefore inhibit glycation reactions [25]. We show here that a number of these compounds inhibit the modification of LDL induced by methylglyoxal and glycolaldehyde, and thereby inhibit lipid accumulation in cultured macrophage cells (i.e. the formation of model foam cells). Complete inhibition is observed, in some cases, with equimolar concentrations of inhibitor and carbonyl compound, suggesting that these species are highly efficacious protective agents.

\section{Materials and methods}

\section{Materials}

Methylglyoxal, glycolaldehyde, metformin (1,1-dimethylbiguanide hydrochloride), hydralazine (1-hydrazinophthalazine), aminoguanidine (guanylhydrazine hydrochloride), Girard's reagent P (1-(carboxy)pyridinium chloride hydrazide), Girard's reagent T ((carboxymethyl)trimethylammonium chloride hydrazide), fatty-acid-free BSA, EDTA, Dulbecco's phosphate-buffered saline (PBS, pH 7.4), methanesulphonic acid, deoxycholic acid, trichloroacetic acid, sodium borohydride, $\beta$-mercaptoethanol, $o$-phthaldialdehyde (OPA), L-homoarginine, amino acid standards and tryptamine were obtained from SigmaAldrich (Castle Hill, NSW, Australia). Precast 4-15\% SDS-PAGE gels and Chelex-100 resin were from Bio-Rad (Regents Park, NSW, Australia). PD10 columns were from Amersham Biosciences (Castle Hill, NSW, Australia). Precast $1 \%$ agarose gels were from Helena Laboratories (Mount Waverly, VIC, Australia). All other chemicals were of analytical grade and all solvents were of HPLC grade. Solutions were prepared using Nanopure water (Milli Q system; Millipore-Waters, Lane Cove, NSW, Australia) pretreated with washed Chelex-100 resin to remove transition metal ions, with the exception of tissue culture reagents, for which Baxter (Old Toongabbie, NSW, Australia) sterile water or PBS was used.

\section{LDL modification}

LDL was isolated, with informed consent, from multiple healthy male and female donors and glycated as described previously [24]. Briefly, sterile LDL (1 mg protein/ml) was incubated with $10 \mathrm{mmol} / 1$ glycolaldehyde or methylglyoxal in chelexed PBS ( $\mathrm{pH} 7.4)$ at $37^{\circ} \mathrm{C}$ under $5 \%(\mathrm{v} / \mathrm{v})$ humidified $\mathrm{CO}_{2}$ for 7 days. EDTA $(50 \mu \mathrm{mol} / \mathrm{l})$ was added to the incubation controls (to prevent artefactual oxidation), but not the aldehyde-treated samples, as rapid reaction occurs between EDTA and these aldehydes. We have previously shown that oxidation is an insignificant process under the conditions employed [24]. Hydrazine compounds $(0-50 \mathrm{mmol} / \mathrm{l})$ were added prior to the aldehyde as indicated, and were present throughout the modification period. Excess reagents were removed before addition of the modified LDL to cells by elution through PD10 columns, according to the manufacturer's instructions, using chelexed PBS.

\section{Characterisation of LDL modifications}

Changes in charge (agarose gels) and cross-linking (reducing SDS-PAGE) of the modified and control LDL 
were quantified as described previously [24]. Amino acid analysis was performed by HPLC analysis using OPA derivatisation after delipidation and methanesulphonic acid hydrolysis [26]. LDL samples $(250 \mu \mathrm{g}$ protein) were prepared for hydrolysis by addition of sodium borohydride $(10 \mu \mathrm{l}, 10 \mathrm{mg} / \mathrm{ml})$, deoxycholic acid $(50 \mu \mathrm{l}, 0.3 \% \mathrm{w} / \mathrm{v})$ and trichloroacetic acid $(100 \mu \mathrm{l}, 50 \% \mathrm{w} / \mathrm{v})$, followed by centrifugation at $4,300 \mathrm{~g}$ for $2 \mathrm{~min}$. Samples were then washed twice with $500 \mu \mathrm{l}$ ice-cold acetone, repelleted by centrifugation at $7,000 \mathrm{~g}$ for $2 \mathrm{~min}$ and dried by vacuum centrifugation. The protein pellets were hydrolysed with methanesulphonic acid $(150 \mu \mathrm{l})$ containing tryptamine $(0.2 \% \mathrm{w} / \mathrm{v})$. L-Homoarginine $(80 \mathrm{nmol})$ was added as an internal standard. Vials were placed in Pico-Tag vessels (Alltech Associates, Baulkham Hills, NSW, Australia), subjected to three cycles of purging $\left(\mathrm{N}_{2}\right.$ gas) and evacuation, then incubated $\left(20 \mathrm{~h}, 110^{\circ} \mathrm{C}\right)$. The samples were subsequently neutralised ( $150 \mu \mathrm{l}, 4 \mathrm{~mol} / \mathrm{l} \mathrm{NaOH})$, filtered, diluted 25 -fold and stored at $4{ }^{\circ} \mathrm{C}$. Analysis was performed within $48 \mathrm{~h}$ by reverse-phase HPLC using a Zorbax ODS $5 \mu \mathrm{m}, 4.6 \times 250 \mathrm{~mm}$ column (Agilent, Forest Hill, NSW, Australia) fitted with a $2 \mathrm{~cm}$ Supelco LC-18 guard cartridge (Sigma-Aldrich, Castle Hill, NSW, Australia). Precolumn derivatisation of samples was performed using a Shimadzu (Shimadzu Oceania, Rydalmere, NSW, Australia) SIL-10A auto-injector that mixed $20 \mu \mathrm{l}$ of an OPA/ $\beta$-mercaptoethanol solution (produced by mixing $1 \mathrm{ml}$ of the former with $5 \mu \mathrm{l}$ of the latter) with $40 \mu \mathrm{l}$ of sample. After $1 \mathrm{~min}, 15 \mu \mathrm{l}$ of derivatised sample was injected. Samples were separated (flow rate of $1 \mathrm{ml} / \mathrm{min})$ using a gradient of buffer A $(20 \%$ methanol, $2.5 \%$ tetrahydrofuran in $20 \mathrm{mmol} / 1$ sodium acetate, $\mathrm{pH} 5.4)$ with $5 \%$ buffer B ( $80 \%$ methanol, $2.5 \%$ tetrahydrofuran in $20 \mathrm{mmol} / \mathrm{l}$ sodium acetate, $\mathrm{pH}$ 5.4) for $7 \mathrm{~min}$; 5-25\% B over $10 \mathrm{~min}$; $25-45 \%$ B over $2 \mathrm{~min}$; $45-$ $50 \%$ B over 8 min; $50-58 \%$ B over 8 min; $58-100 \%$ B over $5 \mathrm{~min} ; 100 \%$ B for $5 \mathrm{~min}$; $100-5 \%$ B over $1 \mathrm{~min}$; and reequilibration at $5 \%$ buffer B for 9 min. Buffers were degassed by vacuum sonication and sparged with helium during chromatography. Derivatised amino acids were detected by fluorescence $\left(\lambda_{\mathrm{ex}} 340 \mathrm{~nm}, \lambda_{\mathrm{em}} 440 \mathrm{~nm}\right.$; Shimadzu RF-10AXL detector) and quantified using amino acid standards with added L-homoarginine and methionine sulphoxide.

\section{Cell studies}

J774A.1 mouse macrophages (TIB-67; American Type Culture Collection, Manassas, VA, USA) were cultured as described previously [24]. Cells were harvested when confluent, replated (12-well plates, $0.5 \times 10^{6}$ cells $/ \mathrm{ml}$ at $1 \mathrm{ml}$ per well) and incubated overnight before exposure to modified LDL or controls $(200 \mu \mathrm{g}$ apoB/ml), for $24 \mathrm{~h}$ in media containing $10 \%$ lipoprotein-deficient serum (prepared as described previously [24]). After exposure, cells were equilibrated $(2 \mathrm{~h})$ using lipoprotein-free media containing $1 \mathrm{mg} / \mathrm{ml} \mathrm{BSA}$ instead of serum. Media samples were then collected, and cells were washed before lysis in water. Cell viability was determined by lactate dehydroge- nase release as described previously [24]. Cell lysates were extracted for analysis of sterols as described previously [24]. Cholesterol and cholesteryl esters were separated by reverse-phase HPLC using isocratic elution (70\% isopropanol/30\% acetonitrile, filtered and degassed) at $1 \mathrm{ml} / \mathrm{min}$ [27]. Eluted materials were detected by UV absorption at $205 \mathrm{~nm}$. Absolute levels of cholesterol and cholesteryl docosahexaenoate, cholesteryl arachidonate, cholesteryl linoleate, cholesteryl palmitate, cholesteryl oleate and cholesteryl stearate were determined by use of standards (Sigma, Castle Hill, NSW, Australia).

\section{Protein assay}

LDL and cell lysate protein concentrations were quantified (60 min incubation at $60^{\circ} \mathrm{C}$ ) using the bicinchoninic acid (BCA) assay (Pierce, Rockford, IL, USA), with BSA as the standard.

\section{Statistical analysis}

Data are expressed as mean \pm SEM from three or more separate experiments with triplicate samples, unless noted otherwise. Statistical analysis was performed with one-way ANOVA and Tukey's post hoc analysis. Statistical significance was indicated by a $p$ value of $<0.05$.

\section{Results}

\section{LDL characterisation}

Incubations of LDL with glycolaldehyde and methylglyoxal were carried out under conditions that give minimal oxidation of the protein, lipids, cholesterol or $\alpha$-tocopherol, but extensive glycation of the apoB protein as determined previously $[24,28]$. We have also shown that these conditions do not affect the relative composition of the particles with respect to apoB, cholesterol and cholesteryl ester [24, 28], and to triglyceride and phospholipid (B. E. Brown and M. J. Davies, unpublished data). Glycation of the apoB molecule was quantified by changes in overall particle charge (relative electrophoretic mobility [REM] on agarose gels), cross-linking (reducing SDSPAGE) and consumption of amino acid residues (HPLC). These changes were subsequently compared with those induced by glycolaldehyde and methylglyoxal in the presence of equimolar or greater concentrations of metformin, aminoguanidine, Girard's reagent $P$, Girard's reagent T and hydralazine (Fig. 1).

The REM data from agarose gels provide data on the overall charge of the LDL particles, and hence the extent of modification of Arg, Lys, His residues and the N-terminal amine group of apoB. As observed previously [24], exposure of LDL to glycolaldehyde or methylglyoxal resulted in significantly larger REM values than incubation controls and native LDL (Figs. 2 and 3a,b). Each of the 
Fig. 1 Structures of compounds studied

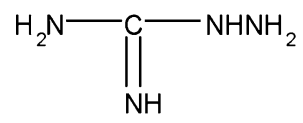

Aminoguanidine

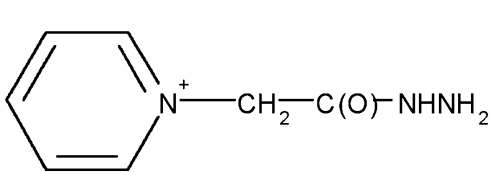

Girard's reagent $P$

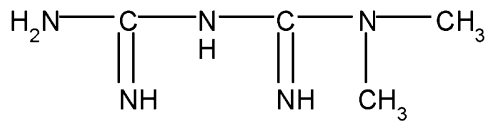

Metformin<smiles>C[N+](C)(C)CC(N)=O</smiles>

Girard's reagent T compounds tested (metformin, aminoguanidine, Girard's reagent $\mathrm{P}$, Girard's reagent T, hydralazine), when included during the LDL modification period at equimolar concentrations to the modifying agent, inhibited these increases (Fig. 3a,b). Aminoguanidine and Girard's reagents P and T were significantly more effective in preventing the changes induced by methylglyoxal than metformin; the REM of LDL in the presence of aminoguanidine, Girard's reagents $P$ and $\mathrm{T}$ was not significantly different from that of the incubation control. Inclusion of hydralazine in incubations with methylglyoxal resulted in precipitation of the LDL. With glycolaldehyde, hydralazine was the most effective in preventing the increases in REM; the REM under these conditions was not significantly different from that of the incubation control. Aminoguanidine and Girard's reagents $\mathrm{P}$ and $\mathrm{T}$ were again more effective $(p<0.05)$ than metformin in preventing the increases induced by glycolaldehyde. Higher concentrations of metformin (Fig. 3c), aminoguanidine (Fig. 3d) and Girard's reagent P (Fig. 3e) resulted in more marked inhibition of the aldehyde-induced changes.

We also examined whether these compounds inhibited aldehyde-induced cross-linking of LDL using SDS-PAGE. Both glycolaldehyde (Fig. 4) and methylglyoxal (data not shown) induce significant cross-linking of LDL when compared with controls [24]. With methylglyoxalmediated cross-linking, greater than equimolar concentrations of metformin and aminoguanidine were required to prevent cross-linking, whereas equimolar concentrations of Girard's reagent $\mathrm{P}$ and $\mathrm{T}$ were effective (data not shown). With glycolaldehyde-treated LDL, aminoguanidine $(10 \mathrm{mmol} / \mathrm{l})$, Girard's reagent $\mathrm{P}(10 \mathrm{mmol} / \mathrm{l})$ and hydralazine $(3 \mathrm{mmol} / \mathrm{l})$ did not prevent apoB cross-linking

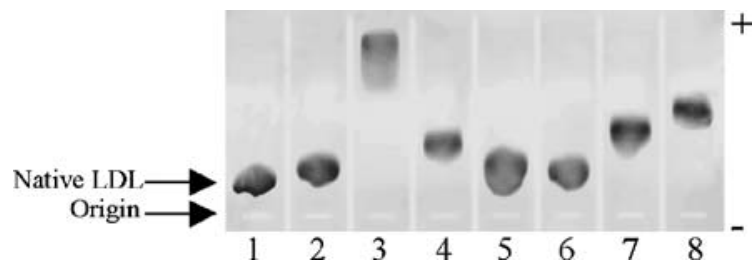

Fig. 2 Agarose gel of native and modified LDL. Lane 1, native LDL; lane 2, LDL plus $50 \mu \mathrm{mol} / 1$ EDTA (incubation control); lane 3, LDL modified with glycolaldehyde ( $10 \mathrm{mmol} / 1$ for 7 days). Lanes $4-8$, as lane 3 except modification carried out in the presence of aminoguanidine (lane 4, $10 \mathrm{mmol} / \mathrm{l}$; lane 5, $25 \mathrm{mmol} / \mathrm{l}$; lane 6 , $50 \mathrm{mmol} / \mathrm{l}$ ), Girard's reagent $\mathrm{P}$ (lane $7,10 \mathrm{mmol} / \mathrm{l}$ ) and hydralazine (lane $8,3 \mathrm{mmol} / \mathrm{l}$ ). Representative gel of three
(Fig. 4, lanes 5, 8 and 9, respectively), whereas higher concentrations of aminoguanidine $(25$ or $50 \mathrm{mmol} / \mathrm{l})$ were effective (Fig. 4, lanes 6 and 7, respectively). Metformin $(\leq 40 \mathrm{mmol} / \mathrm{l})$ and hydralazine $(\leq 10 \mathrm{mmol} / \mathrm{l})$ were ineffective (data not shown).

Changes in the apoB content of Ser, His, Gly, Thr, Arg, Ala, Tyr, Met, Trp, Val, Phe, Ile, Leu and Lys residues, as well as the generation of methionine sulphoxide, were assessed by HPLC. Previous studies have reported changes in Arg, Lys and Trp levels [24, 28]. Data for these residues are presented in Fig. 5. Data for other residues, which were not affected, are not shown. Recovery of the internal standard L-homoarginine was approximately $90 \%$, and no significant differences were observed for the recovery of other amino acid residues (data not shown). With LDL treated with glycolaldehyde, only Lys residues were depleted relative to controls, $10 \mathrm{mmol} / 1$ glycolaldehyde giving $60 \%$ loss (Fig. 5b). Addition of 10,25 or $50 \mathrm{mmol} / 1$ aminoguanidine to such reactions totally prevented the loss of Lys residues; $3 \mathrm{mmol} / \mathrm{l}$ hydralazine was partially protective. The trend towards protection observed for Girard's reagent $P$ failed to reach statistical significance.

\section{Model foam cell formation}

The tested compounds at concentrations used in the above LDL studies did not significantly affect J774A.1 cell viability, as determined by intracellular lactate dehydrogenase release, or total cell protein levels (bicinchoninic acid assay; data not shown). Cells exposed to glycolaldehydemodified LDL, in the absence or presence of these agents, did not have significantly different cell viability or protein levels when compared with controls (data not shown).

Previous studies have shown that incubation of J774A.1 cells with glycolaldehyde- or methylglyoxal-modified LDL (prepared as outlined above, with excess aldehyde removed by column chromatography of the LDL before addition to cells) results in significant cellular accumulation of cholesterol and cholesterol esters [24]. This observation was confirmed: J774A.1 cells exposed to glycolaldehyde-treated LDL had approximately 37\% of their total sterol content present as cholesteryl esters (Fig. 6). Cells exposed to control LDL had less than $7 \%$ of total sterols present as cholesteryl esters. Aminoguanidine $(10 \mathrm{mmol} / \mathrm{l})$, Girard's reagent $\mathrm{P}(10 \mathrm{mmol} / \mathrm{l})$ or hydralazine 
Fig. 3 Relative electrophoretic mobility (REM) of native $(\mathrm{N})$ LDL and LDL modified with $10 \mathrm{mmol} / 1$ methylglyoxal (MG) (a) or glycolaldehyde (GA) (b) for 7 days, compared with native LDL (REM set at 1 ), incubation control (LDL incubated with EDTA) and LDL incubated with MG or GA and $10 \mathrm{mmol} / \mathrm{l}$ of each of metformin (MF), aminoguanidine (AG), Girard's reagent P (GP), Girard's reagent T (GT) or hydralazine $(\mathrm{H})$. Columns with different superscript letters are significantly different by one-way ANOVA $(p<0.05)$ c-f The effect of various concentrations of metformin (c), aminoguanidine (d), Girard's reagent $\mathrm{P}$ (e) and hydralazine (f) on the REM of LDL modified by $10 \mathrm{mmol} / \mathrm{l}$ methylglyoxal (open symbols) or glycolaldehyde (closed symbols) $\mathbf{a}$

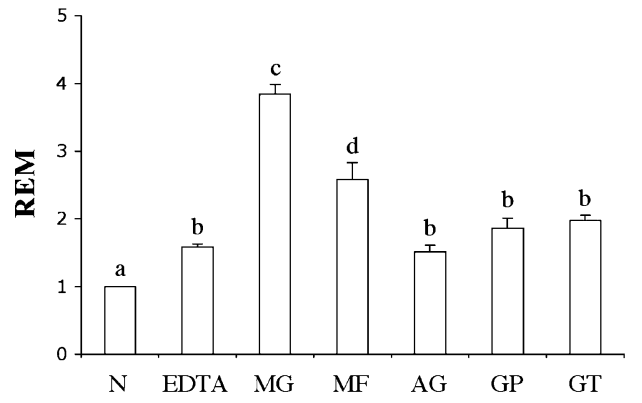

c

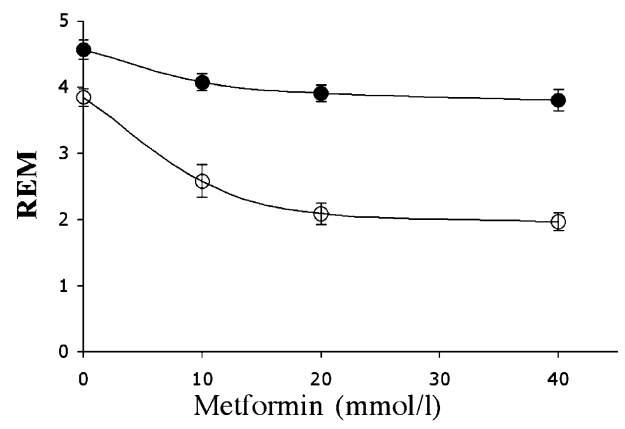

$\mathbf{e}$

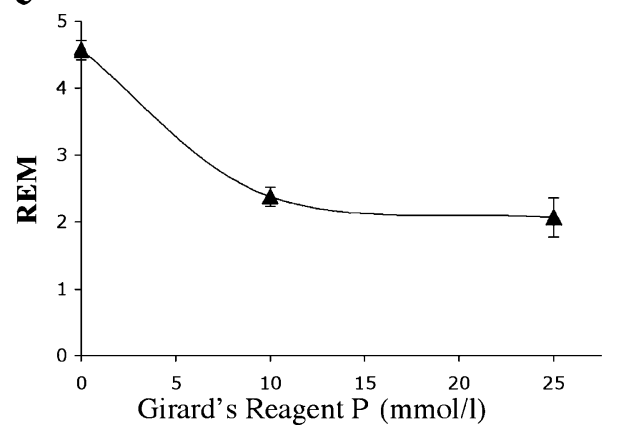

b
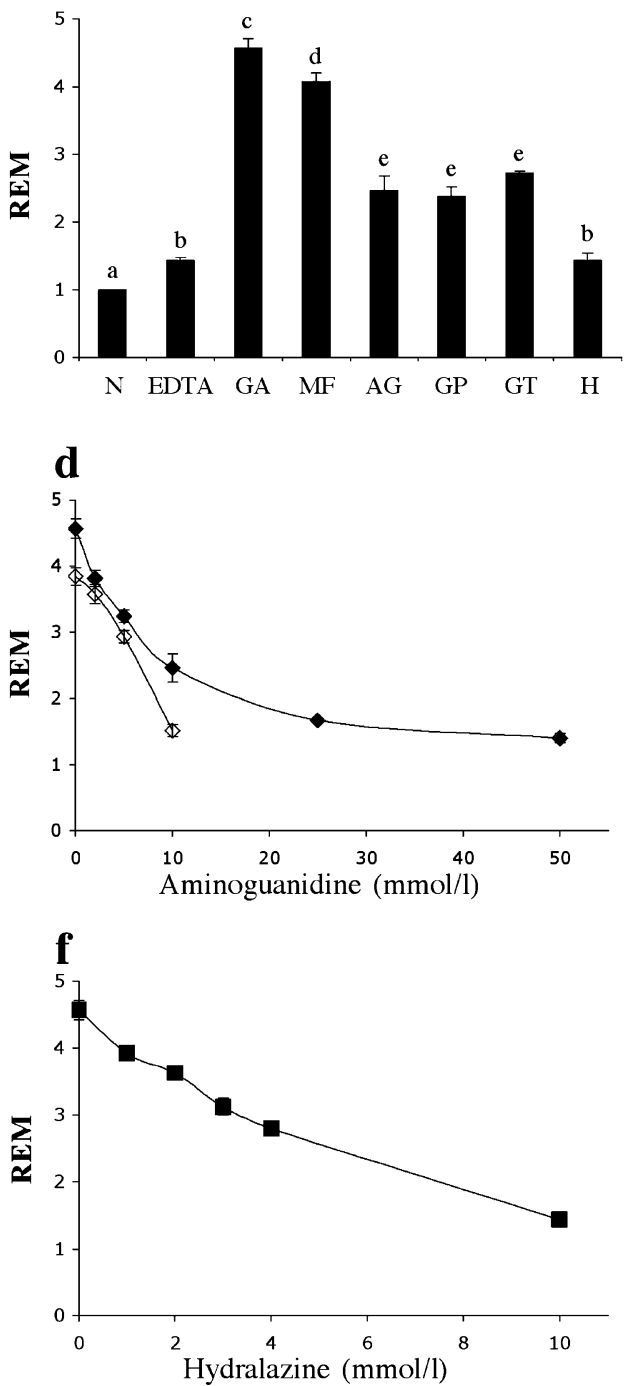

(3 mmol/l) present during the LDL modification phase prevented the subsequent intracellular accumulation of free cholesterol (Fig. 6a) and cholesteryl esters (Fig. 6b). As these modified LDL preparations were subject to column chromatography before addition to the cells, direct effects of excess hydrazine drug on the cells can be discounted. The levels of free cholesterol and cholesteryl esters in these cells were not significantly different from those in cells

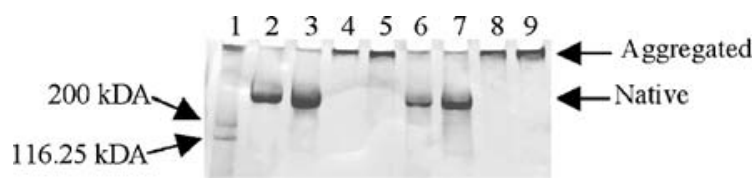

Fig. 4 SDS-PAGE of LDL modified by $10 \mathrm{mmol} / 1$ glycolaldehyde for 7 days in the absence or presence of hydrazine compounds. Lane 1, molecular weight markers $(\mathrm{kDa})$; lane 2, native LDL; lane 3, LDL plus $50 \mu \mathrm{mol} / 1$ EDTA (incubation control); lane 4, LDL modified with glycolaldehyde; lanes 5-9, as lane 4 but with aminoguanidine (lane 5, $10 \mathrm{mmol} / \mathrm{l}$; lane 6, $25 \mathrm{mmol} / \mathrm{l}$; lane 7, $50 \mathrm{mmol} / \mathrm{l}$ ), Girard's reagent $\mathrm{P}$ (lane $8,10 \mathrm{mmol} / \mathrm{l}$ ) or hydralazine (lane $9,3 \mathrm{mmol} / \mathrm{l}$ ). Representative gel of three exposed to incubation control LDL or no LDL (i.e. cholesterol ester content $<7 \%$ of total cholesterol present). These data are consistent with these compounds being highly efficient protective agents.

\section{Discussion}

Previously we have shown that methylglyoxal and glycolaldehyde can modify LDL by glycation, in the absence of significant oxidation (as assessed by the levels of protein side-chain oxidation products, parent lipids, lipid peroxides and alcohols, parent cholesterol, the cholesterol oxidation product 7-ketocholesterol, and $\alpha$-tocopherol $[24,28])$. In the present study we have confirmed that the apoB protein of glycated LDL exhibits increased mobility on agarose gels (i.e. increased REM, as a result of charged residue modification), cross-linking, and loss of Lys residues (as assessed by HPLC). Previous studies have also provided evidence for Arg and Trp modification [24,28]. No significant changes in lipid composition (triglyceride, phospholipid, cholesterol 
a

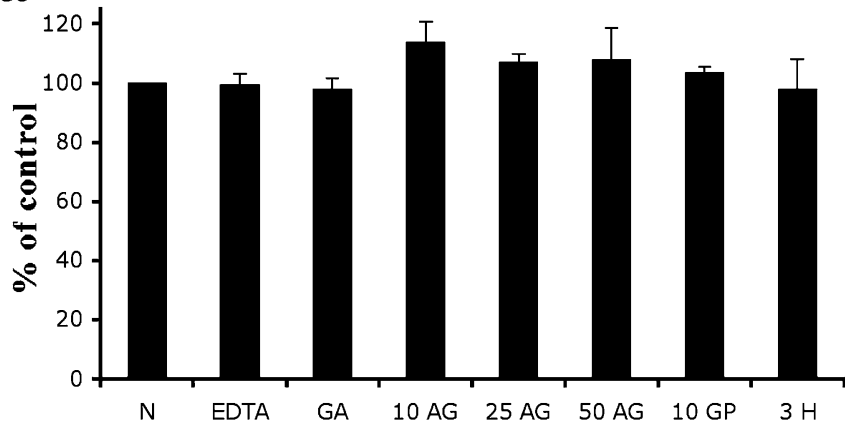

b

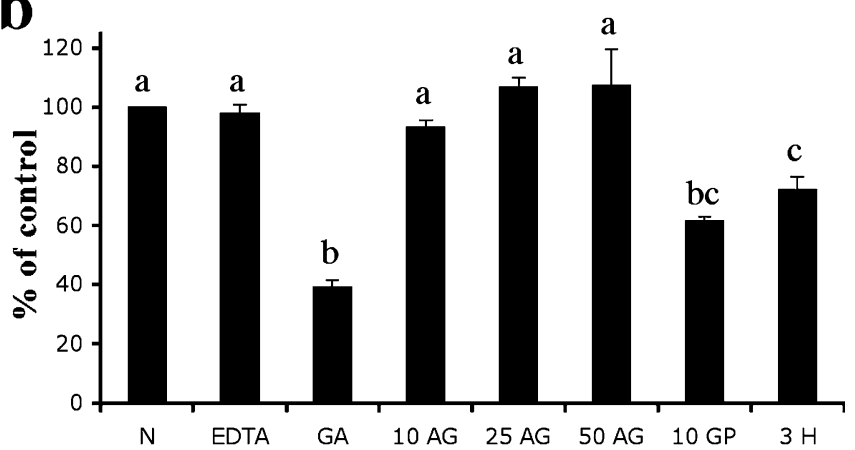

c

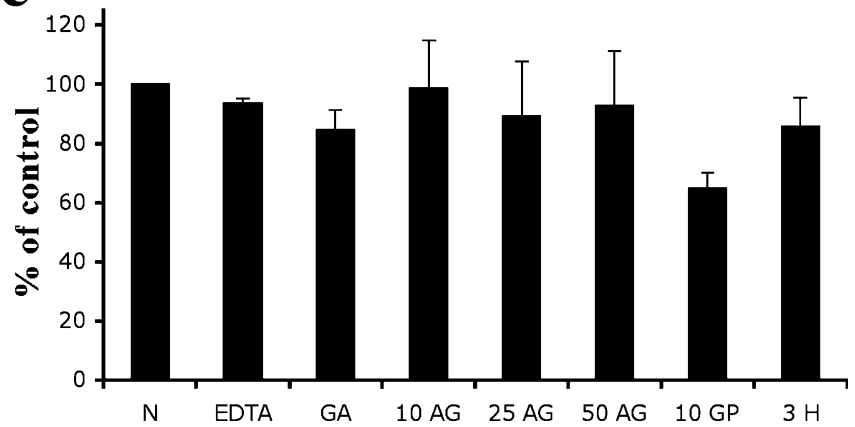

Fig. 5 Arg (a), Lys (b) and Trp (c) levels of apoB modified by $10 \mathrm{mmol} / 1$ glycolaldehyde $(\mathrm{GA})$ in the absence or presence of 10,25 and $50 \mathrm{mmol} / \mathrm{l}$ aminoguanidine $(\mathrm{AG}), 10 \mathrm{mmol} / \mathrm{l}$ Girard's reagent $\mathrm{P}$ (GP) and $3 \mathrm{mmol} / 1$ hydralazine $(\mathrm{H})$ as detected by HPLC. Data are expressed relative to native LDL (N) that contains 148 Arg, 356 Lys and 37 Trp residues [48]; these values are set as $100 \%$. Columns with different superscript letters are significantly different by oneway ANOVA $(p<0.05)$

and cholesteryl esters) or the lipid:protein ratio were detected (B. E. Brown and M. J. Davies, unpublished data). These glycated LDL are recognised by scavenger receptors (other than the LDL receptor) on J774A.1 murine macrophages [29] and primary human monocyte-derived macrophages (B. E. Brown, I. Rashid, D. M. van Reyk and M. J. Davies, unpublished data) giving rise to intracellular accumulation of cholesterol and cholesterol esters. Such lipid-laden cells are models of the foam cells that play a critical role in the development and progression of atherosclerosis. These lipidladen cells contain a percentage of cholesterol esters similar to that in foam cells isolated from lesions (i.e. approximately $40 \%$ of total cholesterol present as esters [24]). It has been proposed that glycation of LDL, and subsequent unregulated cellular uptake of the modified particles, may contribute to $\mathbf{a}$
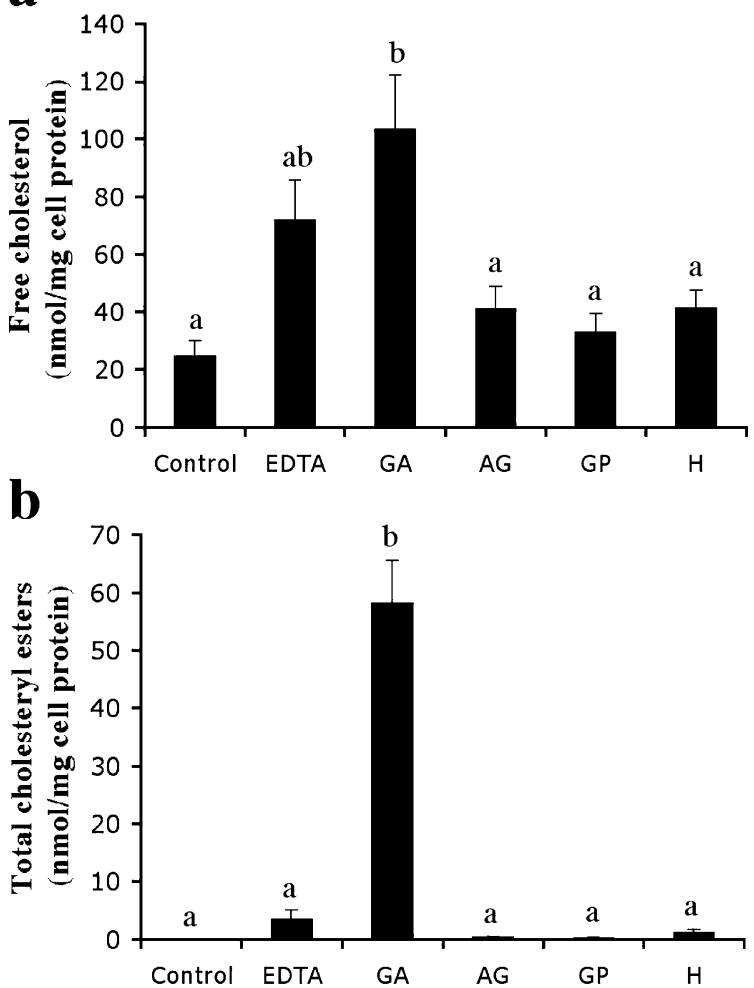

C

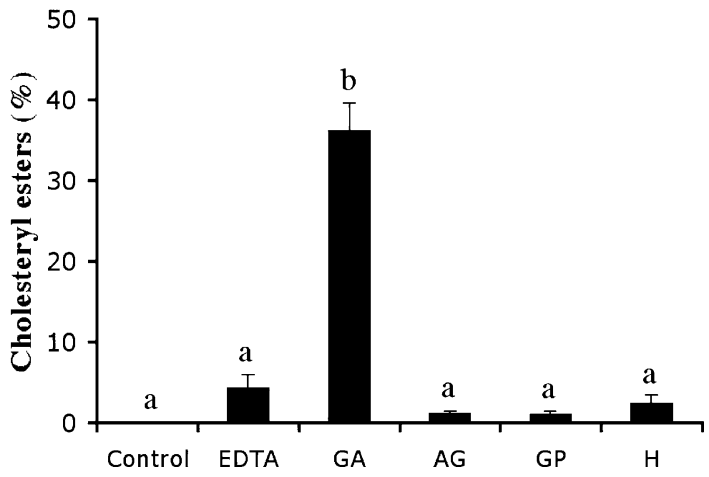

Fig. 6 Free cholesterol (a), total cholesteryl esters (b) and percentage cholesteryl esters of total cholesterol (c) present in J774A. 1 cells, after $24 \mathrm{~h}$ of exposure to $200 \mu \mathrm{g} / \mathrm{ml}$ of LDL that had been previously modified for 7 days by $10 \mathrm{mmol} / \mathrm{l}$ glycolaldehyde (GA). Comparison is with cells exposed to no LDL for the same time periods (Control), incubation control LDL (LDL plus EDTA), or LDL incubated with aminoguanidine (AG, $10 \mathrm{mmol} / \mathrm{l})$, Girard's reagent $\mathrm{P}(\mathrm{GP}, 10 \mathrm{mmol} / \mathrm{l})$, or hydralazine $(\mathrm{H}, 3 \mathrm{mmol} / \mathrm{l})$. Total cholesterol values are the sum of free cholesterol plus total cholesteryl ester levels. Columns with different superscript letters are significantly different by one-way ANOVA $(p<0.05)$

foam cell formation and thus to the increased atherosclerosis observed in people with diabetes. Strategies that prevent LDL glycation may therefore have therapeutic potential.

Hydrazine compounds, which contain the $\mathrm{RNHNH}_{2}$ functional group (Fig. 1), react rapidly with aldehydes and ketones, and this chemistry has found extensive use in the characterisation of carbonyl-containing compounds [30]. Such reactions prevent glycation of LDL induced by reactive aldehydes, glucose and other low-molecular-mass carbonyl compounds $[25,31]$. 
Aminoguanidine has been studied intensively as an antiglycation agent, and reacts rapidly with aldehydes, such as methylglyoxal, thereby preventing AGE formation [32]. Aminoguanidine can also prevent cross-linking of soluble proteins to matrix, AGE-mediated cross-linking of collagen, increases in the AGE matrix content of aortas, and the quantity of plasma proteins cross-linked to matrix [33]. Clinical trials with aminoguanidine (under the name pimagedine) have, however, provided evidence of complications that make it unsuitable for clinical use [32]. Metformin, used clinically as an antihyperglycaemic agent, is structurally related to aminoguanidine and may therefore exhibit some protective actions [25, 31]. Metformin partially inhibits the increase in AGE-related fluorescence detected on reaction of methylglyoxal with albumin [34]. A previous study has reported a $40-50 \%$ reduction in coronary events with metformin treatment, though glycaemic control was not as effective as intensive treatment with sulphonylureas or insulin [35]. The increased methylglyoxal concentrations detected in people with diabetes is significantly reduced by metformin [36], perhaps due to carbonyl trapping reactions [31, 37]. Hydralazine has been employed clinically as an antihypertensive agent, but is known to react with carbonyls $[38,39]$; this is consistent with a potential protective effect against glycation [25]. Girard's reagents $\mathrm{P}$ and $\mathrm{T}$ were examined here as they contain a hydrazine group that is known to be highly reactive with aldehydes and ketones [30]; these materials have not been used therapeutically to our knowledge.

Inclusion of these agents in LDL incubations concurrently with methylglyoxal or glycolaldehyde reduced glycationassociated changes to LDL. With methylglyoxal, the presence of equimolar concentrations of aminoguanidine, or Girard's reagents $\mathrm{P}$ and $\mathrm{T}$, prevented the observed increases in REM of the modified LDL. Higher concentrations of metformin were needed to produce a comparable effect. In LDL cross-linking experiments, greater than equimolar concentrations of metformin and aminoguanidine were required to prevent cross-linking of apoB, whereas equimolar concentrations of Girard's reagents $\mathrm{P}$ and $\mathrm{T}$ were sufficient. These results suggest that hydrazine compounds efficiently prevent the modification of apoB protein residues induced by methylglyoxal [28], thereby preventing the observed increase in net negative charge of the LDL particle and protein cross-linking.

When glycolaldehyde was used as the LDL-modifying agent, hydralazine was the most effective agent in preventing the observed REM increases. Aminoguanidine and Girard's reagents $\mathrm{P}$ and $\mathrm{T}$ provided partial protection against the REM increases, but none of these compounds prevented LDL cross-linking at equimolar concentrations to the aldehyde. Metformin prevented some of the REM increases, but was the least effective of the compound tested. Aminoguanidine completely prevented, and hydralazine offered partial protection against, the loss of Lys residues. Girard's reagent $\mathrm{P}$ was ineffective. With $10 \mathrm{mmol} / 1$ glycolaldehyde, approximately $60 \%$ of the Lys residues of apoB protein were modified. This level of modification has been reported to be sufficient for the recognition of glycolaldehyde-modified
LDL by macrophage scavenger receptors [24, 40]. The observed cellular accumulation of cholesteryl esters from such glycolaldehyde-modified LDL is consistent with these earlier data. Interestingly, none of the compounds tested provided complete inhibition of the changes in LDL particle properties induced by glycation, yet these agents provided virtually complete protection against lipid accumulation in J774A.1 cells. Even in cases where $40 \%$ of Lys residues remained modified, no significant intracellular sterol accumulation was detected, suggesting that there is a dramatic cut-off in scavenger receptor recognition in the region between 40 and $60 \%$ Lys modification (i.e. that there is a threshold value of modification required for recognition of the modified LDL by the scavenger receptors). This has potentially important therapeutic ramifications, as relatively small changes in the extent of LDL modification may have profound effects on the extent of intracellular lipid accumulation by macrophage cells exposed to modified particles.

These studies also demonstrate that apoB cross-linking does not appear to be a key determinant of receptor recognition and intracellular lipid accumulation, as equimolar concentrations (with regard to glycolaldehyde) of aminoguanidine, hydralazine and Girard's reagent $\mathrm{P}$ did not prevent cross-linking of the apoB protein, but did prevent model foam cell formation.

The observed changes in the extent of Lys modification do not correlate well with the other two measures of glycation examined (REM and cross-linking). Aminoguanidine (at $10 \mathrm{mmol} / \mathrm{l}$ ) completely prevented Lys residue loss induced by glycolaldehyde, whereas the REM and cross-linking changes were incompletely inhibited. The REM and cross-linking changes may therefore be dependent on the nature of the products formed from the Lys residues rather than the loss of parent Lys itself. Furthermore, the changes in Arg, Lys and Trp residues on apoB measured by total amino acid analysis (i.e. after acid hydrolysis of the protein) differ significantly from those reported previously using fluorescence assays on 'intact' particles. With the latter technique a greater loss of Lys and Trp residues was detected under identical conditions [28]. The reasons for this discrepancy are not fully understood, but it is possible that the extent of loss detected by direct fluorescence is misleading as a result of contributions from other fluorophores or changes in the environment. It is well established that fluorescent products are generated during glycation [12] and this may result in an overestimation of loss. Alternatively, it is possible that the HPLC and direct fluorescent assays measure different populations; for example, both reversibly and irreversibly modified species in the case of the fluorescence assays, but only irreversibly damaged materials in the total amino acid analysis. Thus, some of the initial (reversible) products may be converted back to the parent amino acid by the strong acid used in the protein hydrolysis. The discrepancies between these methods need to be investigated further to determine which is the more accurate method of assessing amino acid modification. 
The concentrations of aldehydes used in this study are much higher than those reported clinically $[22,23,41]$. The in vivo values, which are in the nano- to micromolar range, are potentially misleading, however, as they (presumably) represent unreacted, steady-state levels of highly reactive species, and the true flux of these compounds may be higher. Subendothelial entrapment of LDL [42-44] may also allow greater extents of LDL modification than observed in plasma, as a result of chronic exposure to low levels of carbonyl compounds. However, the key observation in this study is that equimolar concentrations of the hydrazine compounds, when compared with the reactive aldehyde, are sufficient to completely prevent intracellular lipid accumulation (i.e. model foam cell formation). Furthermore, as incomplete inhibition of LDL modification appears to be sufficient to prevent scavenger receptor recognition and particle uptake, it is possible that even low levels of these carbonyl-scavenging compounds may be beneficial. After oral dosing in humans hydralazine and metformin can reach micromolar concentrations and aminoguanidine concentrations of tens of micromoles [32, 45-47], levels that are considerably in excess of those of the reactive aldehydes (see above). It is therefore conceivable that these compounds may act as efficient scavengers of reactive aldehydes in vivo, especially as it has been demonstrated that equimolar levels of these drugs are sufficient to induce significant protection against aldehyde-mediated LDL modification. Thus, hydrazine compounds and analogues may be worthy of further study as agents to inhibit diabetes-induced atherosclerosis.

Acknowledgements The authors thank the Australian Research Council and Diabetes Australia Research Trust for financial support. B. E. Brown acknowledges receipt of an Australian Postgraduate Award via the University of Sydney. The authors thank C. Hawkins and P. Morgan for assistance with the amino acid analysis.

\section{References}

1. Brownlee M (2001) Biochemistry and molecular cell biology of diabetic complications. Nature 414:813-820

2. World Health Organization (2002) Diabetes mellitus (Fact sheet No. 138). Geneva, WHO

3. Eaton JW, Dean RT (2000) Diabetes and atherosclerosis. In: Dean RT, Kelly DT (eds) Atherosclerosis. Oxford University Press, Oxford, pp 24-45

4. Jenkins AJ, Best JD, Klein RL, Lyons TJ (2004) Lipoproteins, glycoxidation and diabetic angiopathy. Diabetes Metab Res Rev 20:349-368

5. Ross R, Glomset JA (1976) The pathogenesis of atherosclerosis. N Engl J Med 295:369-416

6. Steinberg D (1997) Oxidative modification of LDL and atherogenesis. Circulation 95:1062-1071

7. Li AC, Glass CK (2002) The macrophage foam cell as a target for therapeutic intervention. Nat Med 8:1235-1242

8. Goldstein JL, Ho YK, Basu SK, Brown MS (1979) Binding site on macrophages that mediates uptake and degradation of acetylated low density lipoprotein, producing massive cholesterol deposition. Proc Natl Acad Sci USA 76:333-337

9. Lopes-Virella MF, Klein RL, Virella G (1996) Modification of lipoproteins in diabetes. Diabetes Metab Rev 12:69-90
10. Tomkin GH, Owens D (2001) Abnormalities in apo Bcontaining lipoproteins in diabetes and atherosclerosis. Diabetes Metab Res Rev 17:27-43

11. Lyons TJ, Jenkins AJ (1997) Lipoprotein glycation and its metabolic consequences. Curr Opin Lipidol 8:174-180

12. Baynes JW, Thorpe SR (2000) Glycoxidation and lipoxidation in atherogenesis. Free Radic Biol Med 28:1708-1716

13. Thorpe SR, Baynes JW (2003) Maillard reaction products in tissue proteins: new products and new perspectives. Amino Acids 25:275-281

14. Kawamura M, Heinecke JW, Chait A (1994) Pathophysiological concentrations of glucose promote oxidative modification of low density lipoprotein by a superoxide-dependant pathway. J Clin Invest 94:771-778

15. Chisolm GM, Steinburg D (2000) The oxidative modification hypothesis of atherogenesis: an overview. Free Radic Biol Med 28:1815-1826

16. Baynes JW, Thorpe SR (1999) Role of oxidative stress in diabetic complications - a new perspective on an old paradigm. Diabetes 48:1-9

17. Thornalley PJ, Battah S, Ahmed N, Karachalias N, Agalou S, Babaei-Jadidi R (2003) Quantitative screening of advanced glycation endproducts in cellular and extracellular proteins by tandem mass spectrometry. Biochem J 375:581-592

18. Nagai R, Hayashi CM, Xia L, Takeya M, Horiuchi S (2002) Identification in human atherosclerotic lesions of GA-pyridine, a novel structure derived from glycolaldehyde-modified proteins. J Biol Chem 277:48905-48912

19. Sakata N, Imanaga Y, Meng J et al (1999) Increased advanced glycation end products in atherosclerotic lesions of patients with end-stage renal disease. Atherosclerosis 142:67-77

20. Schleicher ED, Wagner E, Nerlich AG (1997) Increased accumulation of the glycoxidation product $N$ (epsilon)-(carboxymethyl)lysine in human tissues in diabetes and aging. J Clin Invest 99:457-468

21. Thornalley PJ, Langborg A, Minhas HS (1999) Formation of glyoxal, methylglyoxal and 3-deoxyglucosone in the glycation of proteins by glucose. Biochem J 344:109-116

22. Odani H, Shinzato T, Matsumoto JU, Maeda K (1999) Increase in three $\alpha, \beta$-dicarbonyl compound levels in human uremic plasma: specific in vivo determination of intermediates in advanced Maillard reaction. Biochem Biophys Res Commun 256:89-93

23. Atkins TW, Thornally PJ (1989) Erythrocyte glyoxalase activity in genetically obese (ob/ob) and streptozotocin diabetic mice. Diabetes Res 11:125-129

24. Brown BE, Dean RT, Davies MJ (2005) Glycation of lowdensity lipoproteins by methylglyoxal and glycolaldehyde gives rise to the in vitro formation of lipid-laden foam cells. Diabetologia 48:361-369

25. Khalifah RG, Baynes JW, Hudson BG (1999) Amadorins: novel post-Amadori inhibitors of advanced glycation reactions. Biochem Biophys Res Commun 257:251-258

26. Morgan PE, Sturgess AD, Davies MJ (2005) Increased levels of serum protein oxidation and correlation with disease activity in systemic lupus erythematosus. Arthritis Rheum 52:2069-2079

27. Kritharides L, Jessup W, Gifford J, Dean RT (1993) A method for defining the stages of low-density lipoprotein oxidation by the separation of cholesterol- and cholesteryl ester-oxidation products using HPLC. Anal Biochem 213:79-89

28. Knott HM, Brown BE, Davies MJ, Dean RT (2003) Glycation and glycoxidation of low-density lipoproteins by glucose and low molecular weight aldehydes: formation of modified and oxidised proteins. Eur J Biochem 270:3572-3582

29. Guyton JR, Klump KF (1994) Development of the atherosclerosis core region-chemical and ultrastructural analysis of microdissected atherosclerotic lesions from human aorta. Arterioscler Thromb 14:1305-1314

30. March J (1992) Advanced organic chemistry. Wiley, New York

31. Rahbar S, Figarola JL (2003) Novel inhibitors of advanced glycation endproducts. Arch Biochem Biophys 419:63-79 
32. Thornalley PJ (2003) Use of aminoguanidine (Pimagedine) to prevent the formation of advanced glycation endproducts. Arch Biochem Biophys 419:31-40

33. Brownlee M, Cerami A, Vlassara H (1988) Advanced products of nonenzymatic glycosylation and the pathogenesis of diabetic vascular disease. Diabetes Metab Rev 4:437-451

34. Ruggiero-Lopez D, Lecomte M, Moinet G, Patereau G, Lagarde M, Wiernsperger N (1999) Reaction of metformin with dicarbonyl compounds: possible implication in the inhibition of advanced glycation end product formation. Biochem Pharmacol 58:1765-1773

35. UK Prospective Studies Group (1998) Intensive blood-glucose control with sulphonylureas or insulin compared with conventional treatment and risk of complications in patients with type 2 diabetes (UKPDS 33). Lancet 352:837-883

36. Beisswenger PJ, Howell SK, Touchette AD, Lal S, Szwergold BS (1999) Metformin reduces systemic methylglyoxal levels in type 2 diabetes. Diabetes 48:198-202

37. Beisswenger P, Ruggiero-Lopez D (2003) Metformin inhibition of glycation processes. Diabetes Metab 29:S95-103

38. Burcham PC, Fontaine FR, Kaminskas LM, Petersen DR, Pyke SM (2004) Protein adduct-trapping by hydrazinophthalazine drugs: mechanisms of cytoprotection against acrolein-mediated toxicity. Mol Pharmacol 65:655-664

39. Burcham PC, Kaminskas LM, Fontaine FR, Petersen DR, Pyke SM (2002) Aldehyde-sequestering drugs: tools for studying protein damage by lipid peroxidation products. Toxicology 181-182:229-236
40. Jinnouchi Y, Sano H, Nagai R et al (1998) Glycolaldehydemodified low density lipoprotein leads to foam cells via the macrophage scavenger receptor. J Biochem (Tokyo) 123:1208-1217

41. McLellan AC, Thornalley PJ, Benn J, Sonksen PH (1994) Glyoxalase system in clinical diabetes mellitus and correlation with diabetic complications. Clin Sci 87:21-29

42. Proctor SD, Pabla CK, Mamo JCL (2000) Arterial intimal retention of pro-atherogenic lipoproteins in insulin deficient rabbits and rats. Atherosclerosis 1449:315-322

43. Skalen K, Gustafsson M, Rydberg EK, Hulten LM, Wiklund O, Innerarity TL, Boren J (2002) Subendothelial retention of atherogenic lipoproteins in early atherosclerosis. Nature 417: 750-754

44. Williams KJ, Tabas I (1998) The response-to-retention hypothesis of atherogenesis reinforced. Curr Opin Lipidol 9:471-474

45. Karttunen P, Uusitupa M, Lamminsivu U (1983) The pharmacokinetics of metformin: a comparison of the properties of a rapid-release and a sustained-release preparation. Int $\mathrm{J}$ Clin Pharmacol Ther Toxicol 21:31-36

46. Shepherd AM, Ludden TM, McNay JL, Lin MS (1980) Hydralazine kinetics after single and repeated oral doses. Clin Pharmacol Ther 28:804-811

47. Foote EF, Look ZM, Giles P, Keane WF, Halstenson CE (1995) The pharmacokinetics of aminoguanidine in end-stage renal disease patients on hemodialysis. Am J Kidney Dis 25:420-425

48. Esterbauer H, Gebicki J, Puhl H, Jurgens G (1992) The role of lipid peroxidation and antioxidants in oxidative modification of LDL. Free Radic Biol Med 13:341-390 